\title{
Detection of Lard in Ink Extracted from Printed Food Packaging Using Fourier Transform Infrared Spectroscopy and Multivariate Analysis
}

\author{
Syazwani Ramli, ${ }^{1}$ Rosnita A. Talib, ${ }^{1,2}$ Russly A. Rahman, ${ }^{1,2,3}$ Norhazlin Zainuddin, ${ }^{4}$ \\ Siti Hajar Othman, ${ }^{2}$ and Norma M. Rashid ${ }^{1}$ \\ ${ }^{1}$ Laboratory of Halal Science Research, Institute of Halal Products Research, Universiti Putra Malaysia (UPM), \\ Putra Infoport, 43400 Serdang, Malaysia \\ ${ }^{2}$ Department of Process and Food Engineering, Faculty of Engineering, Universiti Putra Malaysia (UPM), 43400 Serdang, Malaysia \\ ${ }^{3}$ Department of Food Technology, Faculty of Food Science and Technology, Universiti Putra Malaysia (UPM), 43400 Serdang, Malaysia \\ ${ }^{4}$ Department of Chemistry, Faculty of Science, Universiti Putra Malaysia (UPM), 43400 Serdang, Malaysia
}

Correspondence should be addressed to Rosnita A. Talib; rosnita@upm.edu.my

Received 26 July 2015; Revised 31 October 2015; Accepted 5 November 2015

Academic Editor: Eugen Culea

Copyright (C) 2015 Syazwani Ramli et al. This is an open access article distributed under the Creative Commons Attribution License, which permits unrestricted use, distribution, and reproduction in any medium, provided the original work is properly cited.

\begin{abstract}
Fourier transform infrared (FTIR) spectroscopy combined with chemometrics was utilised to discriminate the presence of lard in extracted ink of printed food packaging. Two spectral regions (full spectra, 3999-649 $\mathrm{cm}^{-1}$, and combination of two regions, 3110$2630 \mathrm{~cm}^{-1}$ and $1940-649 \mathrm{~cm}^{-1}$ ) of lard, commercial gravure ink, and the blends of both were selected and used to develop a Soft Independent Modelling of Class Analogy (SIMCA) model. The score plots obtained from the Principal Component Analysis (PCA) revealed that the maximum number of factors (7 factors) was needed to explain $84 \%$ of the total variance. SIMCA was employed as the method to classify the samples into their specific groups. Si versus Hi plots showed that the calibration standards can be classified as lard-containing standards. Sample 2 was deduced to have the highest possibility of containing lard, while only samples 5 and 7 cannot be classified as lard-containing samples. These results demonstrated that FTIR spectroscopy, when combined with multivariate analysis, can provide a rapid method with no excessive sample preparation to detect the presence of lard in ink of foodstuff packaging.
\end{abstract}

\section{Introduction}

Printing inks are generally used on label-printed packaging as a means of information communication and also as graphical designs of the packaging to attract consumers. Basically, printing inks comprise a complex mixture of three main components: pigments (5-30\%), binders or resins $(5-50 \%)$, and carriers (15-80\%). Carriers, or vehicles for oil-based inks, are usually made up of oils and fats. Along with these components, additives such as oils and drying agents can be added at concentrations up to $10 \%$ to formulate the desired inks in order to satisfy end-use properties [1]. The oils are generally triglycerides, minerals, and monoesters that can be derived from different sources with various functional characteristics such as antiblocking and antislip properties [2].
Compared to the likes of vegetable oils, lard (pig fat) has exceptional properties such as wider plastic ranges, which indicates its workability over a wide range of temperatures, and it is cheaper; thus, it is common to add lard or lard blended with other oils to reduce production cost of printing inks [3].

However, the presence of animal fats, particularly lard, in consumer goods including foods, cosmetics, and pharmaceuticals has received special attention by Muslim and Jewish communities and many other consumers due to the religious prohibition and health-related dietary restrictions. The awareness about this matter has increased over the years, not only among people from certain religious beliefs or communities, but also worldwide [4]. In order for a product to be certified as Halal, all processes and materials involved 
in the manufacture must be Halal compliant [5]. Ink is one of the materials used in production of foodstuff packaging that always comes in contact with human skin, so ensuring the purity of the ink should receive similar attention. Knowing that the manufacturing of inks involves the use of fats and oils, the origin of the resources could be questionable.

This study is focused on lard characterization. Due to reasons including the prohibition of exposure to lard and the existence of organic and inorganic components in ink compositions, development of a fast and reliable analytical method for lard detection and characterization is required, and Fourier transform infrared (FTIR) is one of the preferred methods. In addition, FTIR has other advantages such as being a sensitive, well-established, and nondestructive process, generally requiring only simple sample preparation [6]. FTIR is widely used for characterisation of fats and oils due to the variations of peak intensities and the exact frequencies at which the maximum absorbance of peaks appears, in accordance with the nature and structure of the sample [7]. For ink-related research, FTIR has been utilised in certain areas, such as in forensic examination as conducted by Techabowornkiat and Chaikum [8] and Dirwono et al. [9]. Nevertheless, to the best of our knowledge, research on food packaging ink using FTIR has yet to be done.

The main aim of this study was to develop a rapid detection method coupled with a chemometrics approach to detect the presence of lard in the printing ink of food packages using FTIR spectroscopy. This overall goal can be achieved using a set of objectives as follows: to investigate the FTIR unique characteristics of lard relative to those of other sources of triglycerides and waxes, to develop a FTIR detection method for detecting intentionally added lard in a mixture of commercial gravure inks, and to investigate the use of FTIR spectroscopy coupled with multivariate analysis to detect the potential presence of lard in the ink of commercially printed food packaging films. By applying a spectroscopic method conjugated with multivariate analysis, we aimed to obtain more information about the main components of the samples examined.

\section{Materials and Methods}

2.1. Lard Preparation. Lard was rendered from the adipose tissue of pigs at $90-100^{\circ} \mathrm{C}$ for 2 hours in the oven according to Rohman and Che Man [10]. The melted fats were strained through triple-folded muslin cloth and dried by the addition of anhydrous sodium sulfate $\left(\mathrm{Na}_{2} \mathrm{SO}_{4}\right)$. Fats were subsequently subjected to centrifugation (3000 rpm, $20 \mathrm{~min}$ ). The fat layer was decanted, shaken vigorously, and then centrifuged again before being filtered using Whatman filter paper.

2.2. Deinking. The plastic packaging samples obtained were cut into $4 \mathrm{~cm}^{2}(2 \times 2 \mathrm{~cm})$ film strips. The films were then soaked individually in sodium hydroxide $(\mathrm{NaOH})$ and placed in a water bath for 2 hours at $60^{\circ} \mathrm{C}$. Several ceramic rings were put into the beaker which contained $\mathrm{NaOH}$ and the film to act as abrasive agent and placed on the magnetic stirrer to be stirred until the ink detached from the film. The resulting mixture of detached ink and $\mathrm{NaOH}$ was centrifuged at $6000 \mathrm{rpm}$ for 5 minutes. The supernatants were discarded. The detached inks were then dried in an oven at $40^{\circ} \mathrm{C}$, ready for further test via FTIR.

2.3. FTIR Analysis. The spectral bands of commercial gravure ink and the blends of this ink with lard at different concentrations were scanned using a Nicolet 6700 FTIR spectrometer (Thermo Nicolet Corp., USA) equipped with a detector of deuterated triglycine sulfate (DTGS), a potassium bromate $(\mathrm{KBr}) /$ germanium beam splitter, and OMNIC software (Version 7.0 Thermo Nicolet). FTIR data were collected from 32 scans at a resolution of $4 \mathrm{~cm}^{-1}$ with a strong apodization throughout the $4000-650 \mathrm{~cm}^{-1}$ frequency region. A background air spectrum was subtracted from these spectra. The calibration standards were prepared by spiking lard of different concentrations (0.1-20\%) into the commercial gravure ink.

Printed packaging samples were scanned in a Nicolet 6700 spectrometer system from Thermo Electron Corp., USA, fitted with a preserved and desiccated interferometer. The sampling compartment was a Smart OMNI-Sampler for single reflection ATR analysis using the $\mathrm{KBr}$ method. The Smart OMNI-Sampler utilises a spherical ATR germanium crystal as the sampling surface with a $2 \mathrm{~mm}$ diameter and a 45-degree crystal angle, producing a penetration depth (infrared beam) of $0.67 \mu \mathrm{m}$. After every scan, a new reference air background spectrum was collected. This spectrum was recorded as the absorbance value at each data point.

2.4. Quantitative Analysis. The Soft Independent Modelling of Class Analogy (SIMCA) was performed using Unscrambler $\mathrm{X}$ version 10.3. The calibration standards included different percentages of blended lard in the ink formulation. All of the samples were analysed using a FTIR spectrometer. The Principal Component Analysis (PCA) was executed as the basis for SIMCA. The spectral data were arranged in two excel tables and imported into the Unscrambler X software. The model was explored to determine its ability to classify the calibration standards and samples into their respective groups, thus detecting the possible presence of lard in the extracted ink samples.

\section{Result and Discussion}

3.1. Spectral Data. Each peak of the FTIR spectra corresponds to a functional group and exhibits the characteristic bands of this group. Figure 1 illustrates the mid-region FTIR spectrum of lard $\left(4000-650 \mathrm{~cm}^{-1}\right)$.

Lard can be identified from the peaks and shoulders that are attributed to specific functional groups, composition, length, and degree of unsaturation [11]. The predominant spectral features of lard are observed at $3006 \mathrm{~cm}^{-1}, 2921 \mathrm{~cm}^{-1}$ (C-H asymmetrical stretch), $2852 \mathrm{~cm}^{-1}$ (C-H symmetrical stretch), $1749 \mathrm{~cm}^{-1}$ ( $\mathrm{C}=\mathrm{O}$ stretch), $1454 \mathrm{~cm}^{-1}$ (C-H bend), $1166 \mathrm{~cm}^{-1}$ (C-O stretch and C-H bend), and $709 \mathrm{~cm}^{-1}$ (C-H bend). The significant group frequencies of lard are attributed 


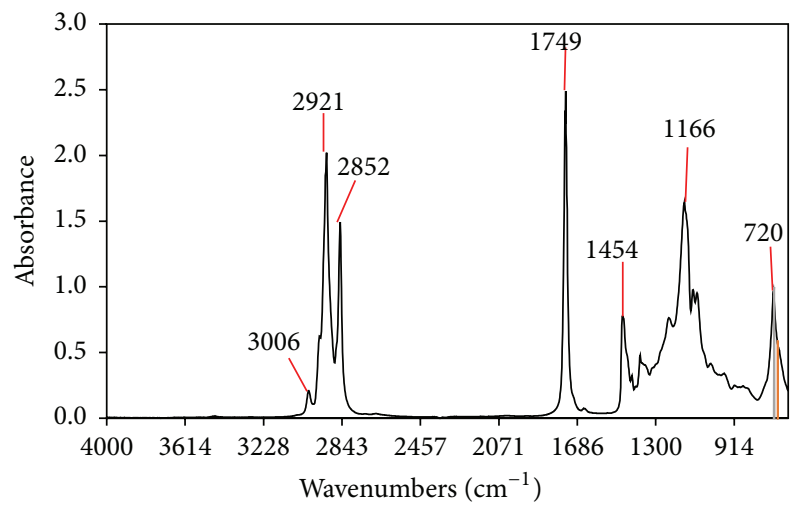

Figure 1: Mid-region infrared spectrum of lard.

to saturated and monounsaturated triglyceride [12]. Coates and Meyers concluded that the strong methylene and methyl band at $1470 \mathrm{~cm}^{-1}$, the weak methyl band at $1380 \mathrm{~cm}^{-1}$, and the methylene rocking vibration at $725-720 \mathrm{~cm}^{-1}$ indicate a long chain linear aliphatic structure [13]. In addition, any band structures observed between 3150 and $3000 \mathrm{~cm}^{-1}$ are almost exclusively indicative of unsaturation $(\mathrm{C}=\mathrm{C}-\mathrm{H})$ or aromatic rings. Thus, the characteristic peaks of saturated and unsaturated triglyceride are observed in the lard spectra. The small peaks at 3006 and $1097 \mathrm{~cm}^{-1}$ are due to the vibrations of $=\mathrm{C}-\mathrm{H}$ (cis) and $-\mathrm{C}=\mathrm{C}-($ cis $)$, respectively. This major characteristic peak of lard is due to the high proportion of monounsaturated acyl groups of oleic acid (C18:1) [14, 15]. Additionally, the most intense feature of the entire spectrum is observed at $1749 \mathrm{~cm}^{-1}$ and represents a carbonyl compound from the ester group.

Figure 2 illustrates the comparison between lard, commercial gravure ink, and ink with addition of $5 \% \mathrm{w} / \mathrm{w}$ of lard at the mid-infrared region of $4000-650 \mathrm{~cm}^{-1}$. The spectra exhibit some peaks at approximately $3420 \mathrm{~cm}^{-1}$ that are indicative of hydroxyl $(\mathrm{O}-\mathrm{H})$ groups and some small and medium peaks in the range of $3050-3000 \mathrm{~cm}^{-1}$ that arise from $=\mathrm{C}-\mathrm{H}$ (trans) and $=\mathrm{C}-\mathrm{H}$ (cis) groups, respectively. Meanwhile, the $\mathrm{C}-\mathrm{H}$ asymmetrical and symmetrical stretches are observed at $2920 \mathrm{~cm}^{-1}$ and $2854 \mathrm{~cm}^{-1}$ for the alkane groups of the ink. The peak at $1747 \mathrm{~cm}^{-1}$ is due to $\mathrm{C}=\mathrm{O}$ stretching, whereas the peaks at $1647 \mathrm{~cm}^{-1}$ and $1539 \mathrm{~cm}^{-1}$ correspond to vibration of $\mathrm{N}-\mathrm{H}_{1}$ amines. Additionally, the peak at $1454 \mathrm{~cm}^{-1}$ is attributed to $\mathrm{C}-\mathrm{H}$ bending that at $1370 \mathrm{~cm}^{-1}$ corresponds to $-\mathrm{C}-\mathrm{H}\left(\mathrm{CH}_{3}\right)$ symmetrical bending and the small peak at approximately $1319 \mathrm{~cm}^{-1}$ arises from $-\mathrm{C}-\mathrm{H}\left(\mathrm{CH}_{3}\right)$ bending. Moreover, the vibrational peaks at 1240, 1119, and $1038 \mathrm{~cm}^{-1}$ are attributed to the stretching vibration of the $\mathrm{C}-\mathrm{O}$ groups in the ester. The other peaks of the ink spectrum at $947,886,812$, and $715 \mathrm{~cm}^{-1}$ correspond to $\mathrm{N}-\mathrm{H}_{1,2}$ amines and $\mathrm{C}-\mathrm{H}$ bending.

The differences between commercial gravure ink and lard augmented ink are apparent from the doublet peak at 1119 and $1089 \mathrm{~cm}^{-1}$ that is present in lard augmented ink and results from the overlapping of the methylene rocking vibration

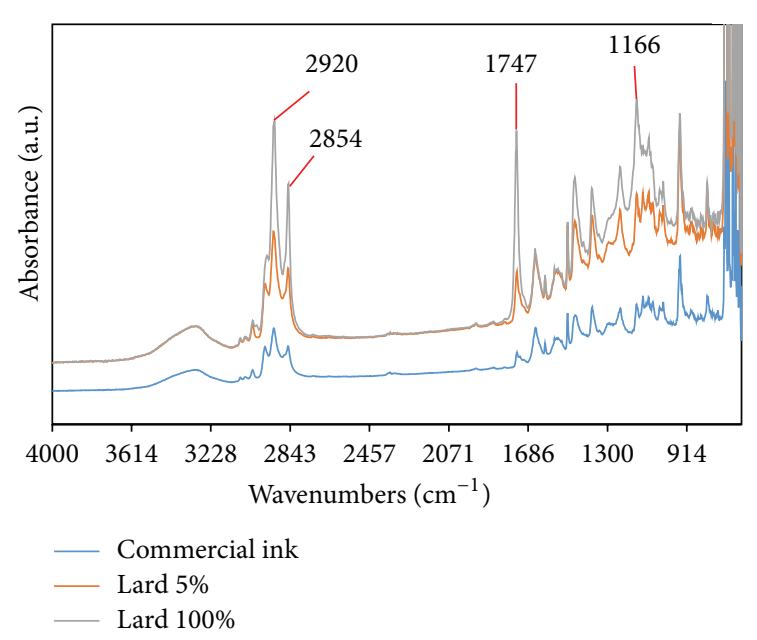

FIgURE 2: Comparison between lard, commercial gravure ink, and lard augmented ink spectra.

(saturated acyl groups) and the out-of-plane bending vibration of cis-disubstituted olefins $(\mathrm{C}-\mathrm{H}$ bending oleic acyl group).

Figure 3 represents the FTIR spectra of commercially printed package samples measured using the ATR accessory. The oil features were observed for all samples in the 3000$2800 \mathrm{~cm}^{-1}, 1800-1700 \mathrm{~cm}^{-1}$, and $1300-600 \mathrm{~cm}^{-1}$ regions, but the peaks were small. Guillén and Cabo [16] and Pan and Nguyen [1] concluded that the FTIR spectra of oil exhibit peaks at $2925,2855,1460,1375,1237,1160,1098,914$, and $720 \mathrm{~cm}^{-1}$ representing the alkane (C-H stretching) or acrylic $\left(-\mathrm{CH}_{2}\right)$ functional groups as part of the saturated hydrocarbon portion of the molecule. The additional $1747 \mathrm{~cm}^{-1}$ peak represents the carbonyl $\mathrm{C}=\mathrm{O}$ stretching. The bands at $3200-3700 \mathrm{~cm}^{-1}$ represent the hydroxyl group $(\mathrm{O}-\mathrm{H})$ at different concentrations, those at $1627 \mathrm{~cm}^{-1}$ and $1559 \mathrm{~cm}^{-1}$ are due to $\mathrm{N}-\mathrm{H}_{1}$ amines, the peak at $1384 \mathrm{~cm}^{-1}$ is due to the $\mathrm{C}-\mathrm{H}$ deformation, and the peak at $620 \mathrm{~cm}^{-1}$ is due to $\mathrm{N}-$ $\mathrm{H}_{1,2}$ amines. These amine groups correspond to amines and ammonia, the key components of the water-based ink that control stability and performance [17]. Tables 1 and 2 show the characteristic functional groups assignment for lard and commercial ink.

3.2. Quantitative Data. The data were prepared to establish a classification model using multivariate analyses by means of Soft Independent Modelling of Class Analogy (SIMCA). Two spectral regions (full spectra, $4000-650 \mathrm{~cm}^{-1}$, and combination of two regions, $3110-2630 \mathrm{~cm}^{-1}$ and $1940-649 \mathrm{~cm}^{-1}$ ) of lard, commercial gravure ink, and the blends of both were selected and arranged in their respective tables. The combined spectral data was pretreated to correct the baseline shift using the MSC/EMSC task which corrected the spectra for scatter effects in the Unscrambler X software. All the spectral data were then subjected to the Principal Component Analysis (PCA) to further explore and describe the data.

Figure 4 shows the score plot from the pretreated spectral data PCA. It is obvious that the plot for lard is located 
TABLE 1: Characteristic functional groups assignment of lard.

\begin{tabular}{lcc}
\hline Wavenumbers $\left(\mathrm{cm}^{-1}\right)$ & Functional group & Mode of vibration/assignment \\
\hline 721 & $-\left(\mathrm{CH}_{2}\right)_{n}-,-\mathrm{HC}=\mathrm{CH}-(\mathrm{cis})$ & Rocking, bending out \\
1096 & $-\mathrm{C}-\mathrm{H}$ & Bending \\
1160 & $=\mathrm{C}-\mathrm{H}(\mathrm{cis})$ & Symmetric rocking \\
1377 & $-\mathrm{C}-\mathrm{H}\left(\mathrm{CH}_{3}\right)$ & Symmetric bending \\
1464 & $-\mathrm{C}-\mathrm{H}\left(\mathrm{CH}_{2}, \mathrm{CH}_{3}\right)$ & Bending \\
1747 & $-\mathrm{C}=\mathrm{O}($ ester $)$ & Stretching \\
$2850-2980$ & $-\mathrm{C}-\mathrm{H}\left(\mathrm{CH}_{2}, \mathrm{CH}_{3}\right)$ & Symmetric and asymmetric stretching \\
3007 & $-\mathrm{C}-\mathrm{H}\left(\mathrm{CH}_{2}, \mathrm{CH}_{3}\right)$ & Symmetric and asymmetric stretching \\
\hline
\end{tabular}

TABLE 2: Characteristic functional groups assignment of commercial ink.

\begin{tabular}{lcc}
\hline Wavenumbers $\left(\mathrm{cm}^{-1}\right)$ & Functional group & Mode of vibration/assignment \\
\hline $700-610$ & $-\mathrm{C} \equiv \mathrm{C}-\mathrm{H}: \mathrm{C}-\mathrm{H}$ alkynes & - \\
$1200-1000$ & $\mathrm{C}-\mathrm{O}, \mathrm{C}-\mathrm{O}-\mathrm{C}$ & Stretching, asymmetric stretching \\
1466,1369 & $\mathrm{C}-\mathrm{H}$ & Deformation \\
1720 & $\mathrm{C}=\mathrm{O}$ (carbonyl group) & - \\
$3575-3125$ & $\mathrm{O}-\mathrm{H}$ (hydroxyl group) & - \\
\hline
\end{tabular}

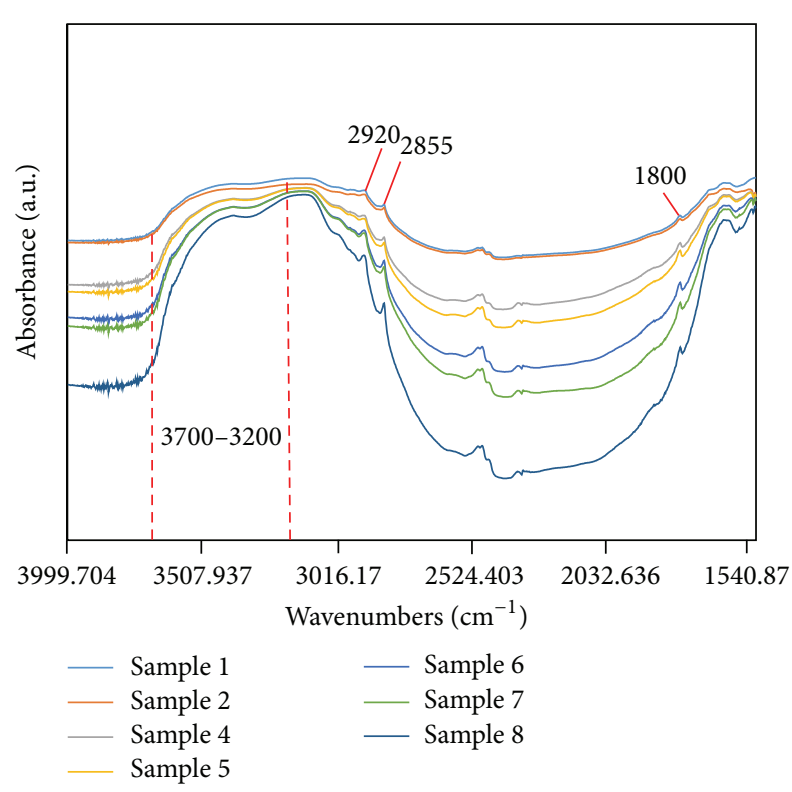

FIGURE 3: FTIR spectra of ink extracts of commercially printed packaging samples.

quite far from the calibration standards, while the plot for commercial ink is clustered together with the calibration standards. The plots were located in that fashion due to the calibration standards containing more percentage of ink than lard. The first and second factors, or principal components, explained only $41 \%$ and $11 \%$ of the total variance, respectively, indicating that the model needs more factors to better explain the variance. Seven factors, which is the maximum number of factors allowed in the analysis, explained $84 \%$ of the total variance collectively.

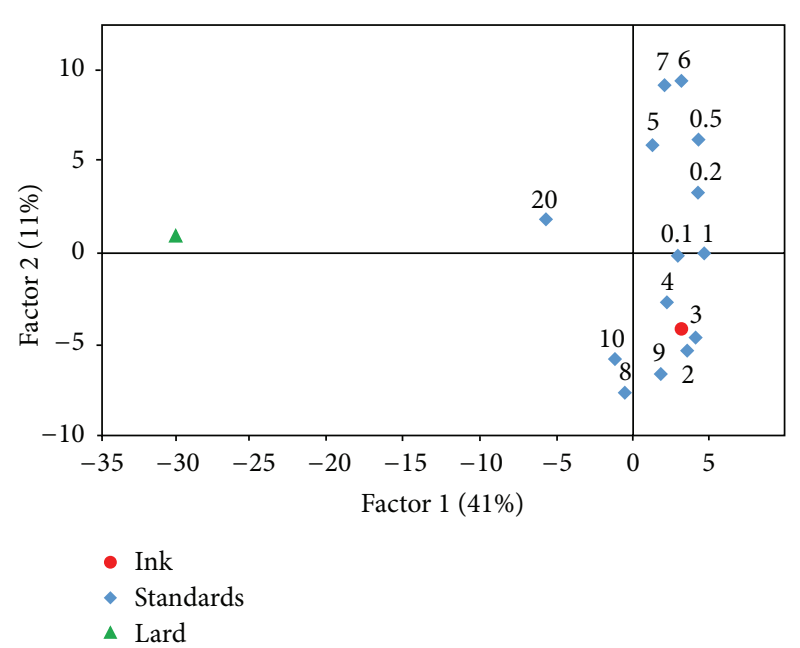

FIGURE 4: Score plots of pretreated spectral data of lard, commercial gravure ink, and calibration standards (0.1-20).

Soft Independent Modelling of Class Analogy (SIMCA) is a method derived from the evaluation of the principal components of each data category, setting up a critical distance with probabilistic meaning and the calculation of the distance of each object from the model of each group. The Si (square root of the residual variance of the sample) is the measurement of the distance of a sample to the modeled group, while the $\mathrm{Hi}$ (leverage) expresses how a difference in the sample can be considered from the other class members. The model distance shows how far different two models are from each other. Normally, a model distance larger than 3 or more shows that two models are sufficiently different to be used to separate them [18].

Discriminant analysis by means of SIMCA was employed to classify the samples into their specific groups based on 


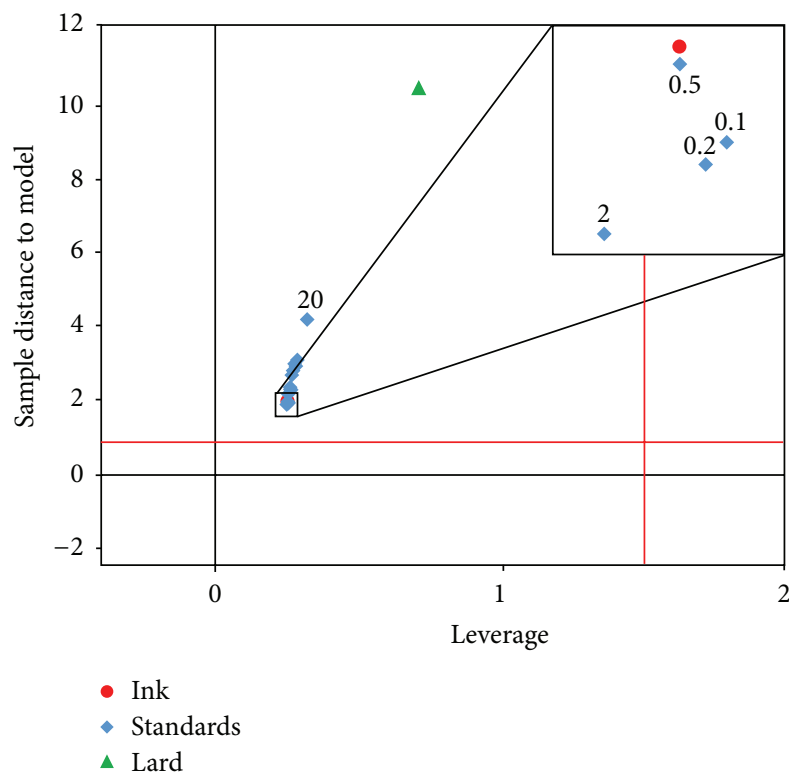

(a)

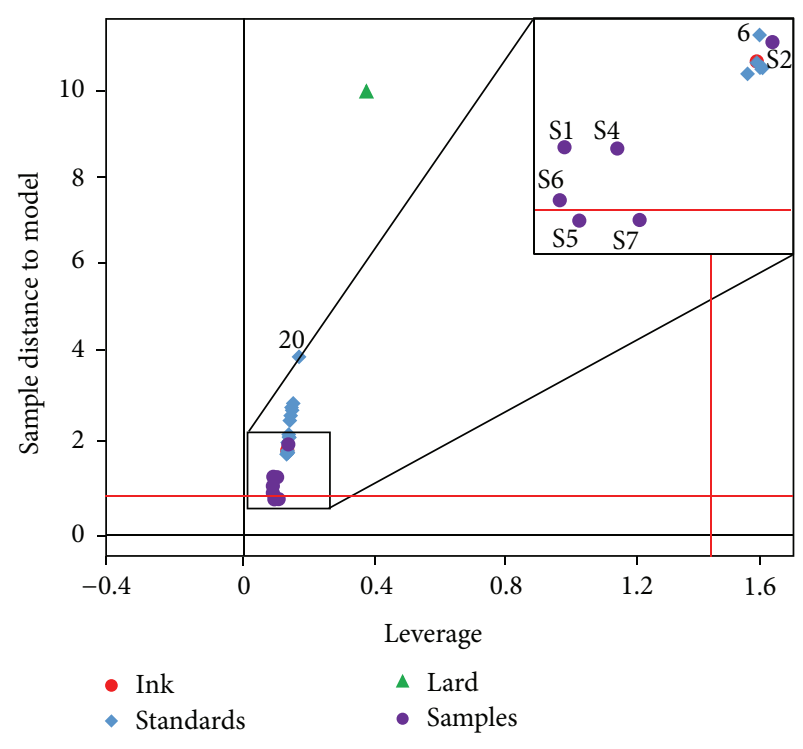

(b)

Figure 5: Si versus $\mathrm{Hi}$ plots for (a) lard, commercial gravure ink, and calibration standards (0.1-20) and (b) calibration standards with the extracted ink samples (S1-S7).

the result of PCA. Si versus $\mathrm{Hi}$ plot generated in Figure 5(a) shows that the calibration standards were clustered together in a box region with both lard and commercial ink. In the score plots generated from the PCA, the plot for lard was located far from the calibration standards indicating that the calibration standards did not seem to contain lard, leading to an early assumption that the calibration standards blends were faulty. The Si versus $\mathrm{Hi}$ plot in Figure 5(a) indicates that the calibration standards can be identified as lard-containing standards, hence proving that the method can be used to classify the samples and eventually detecting lard adulteration. Figure 5(b) shows the Si versus $\mathrm{Hi}$ plot for samples in comparison with the calibration standards. It can be observed that all the samples except for samples 5 and 7 were plotted in a box region with lard and the calibration standards. Sample 2 has the highest possibility to contain lard since it was plotted nearest to the plots of calibration standards, particularly the standards containing $6 \%$ of lard concentration.

\section{Conclusions}

It can be concluded that FTIR spectroscopy in combination with multivariate analysis can provide a rapid method with no excessive sample preparation to discriminate the presence of lard in ink of foodstuff plastic packaging. The discriminant analysis executed was able to classify the samples into their specific groups, hence enabling discrimination of lard presence. From the results, sample 2 was deduced as having the highest potential of containing lard, while only samples 5 and 7 cannot be identified as lard-containing samples. The method is also low in cost and usage of chemicals and hence can be taken into account as green analytical chemistry.

\section{Conflict of Interests}

The authors declare that there is no conflict of interests regarding the publication of this paper.

\section{Acknowledgments}

The author (Syazwani Ramli) would like to thank Universiti Putra Malaysia (UPM) for granting the Graduate Research Fellowship (GRF) Award and The Ministry of Higher Education of Malaysia for funding this research through Fundamental Research Grant Scheme (Project Code 02-02-131369FR).

\section{References}

[1] J. Pan and K. L. Nguyen, "Development of the photoacoustic rapid-scan FT-IR-based method for measurement of ink concentration on printed paper," Analytical Chemistry, vol. 79, no. 6, pp. 2259-2265, 2007.

[2] H. Koivula, J. S. Preston, P. J. Heard, and M. Toivakka, "Visualisation of the distribution of offset ink components printed onto coated paper," Colloids and Surfaces A: Physicochemical and Engineering Aspects, vol. 317, no. 1-3, pp. 557-567, 2008.

[3] L.-Z. Cheong, H. Zhang, Y. Xu, and X. Xu, "Physical characterization of lard partial acylglycerols and their effects on melting and crystallization properties of blends with rapeseed oil," Journal of Agricultural and Food Chemistry, vol. 57, no. 11, pp. 5020-5027, 2009.

[4] Titan Chemicals Corp Bhd, "Halal Polyolefins Resin-Press Release," November 2015, http://disclosure.bursamalaysia.com/ FileAccess/apbursaweb/download/?name=EA_GA_Attachments\&id=26963. 
[5] M. S. A. Talib and M. R. M. Johan, "Issues in halal packaging: a conceptual paper," International Business and Management, vol. 5, no. 2, pp. 94-98, 2012.

[6] E. Lukitaningsih, M. Sa'adah, Purwanto, and A. Rohman, "Quantitative analysis of lard in cosmetic lotion formulation using FTIR spectroscopy and partial least square calibration," Journal of the American Oil Chemists' Society, vol. 89, no. 8, pp. 1537-1543, 2012.

[7] Y. B. C. Man, A. Rohman, and T. S. T. Mansor, "Differentiation of lard from other edible fats and oils by means of Fourier transform infrared spectroscopy and chemometrics," Journal of the American Oil Chemists' Society, vol. 88, no. 2, pp. 187-192, 2011.

[8] K.-U. Techabowornkiat and N. Chaikum, "Forensic examination of blue ballpoint pen inks on various surfaces by ATR FTIR microscopy," in Proceedings of the 20th National Grad Research Conference, pp. 1-7, Salaya, Thailand, February 2011.

[9] W. Dirwono, J. S. Park, M. R. Agustin-Camacho et al., "Application of micro-attenuated total reflectance FTIR spectroscopy in the forensic study of questioned documents involving red seal inks," Forensic Science International, vol. 199, no. 1-3, pp. 6-8, 2010.

[10] A. Rohman and Y. B. Che Man, "The optimization of FTIR spectroscopy combined with partial least square for analysis of animal fats in quartenary mixtures," Spectroscopy, vol. 25, no. 3-4, pp. 169-176, 2011.

[11] C. Cordella, I. Moussa, A.-C. Martel, N. Sbirrazzouli, and L. Lizzani-Cuvelier, "Recent developments in food characterization and adulteration detection: technique-oriented perspectives," Journal of Agricultural and Food Chemistry, vol. 50, no. 7, pp. 1751-1764, 2002.

[12] A. De Leonardis, V. Macciola, G. Lembo, A. Aretini, and A. Nag, "Studies on oxidative stabilisation of lard by natural antioxidants recovered from olive-oil mill wastewater," Food Chemistry, vol. 100, no. 3, pp. 998-1004, 2007.

[13] J. Coates and R. A. Meyers, "Interpretation of infrared spectroscopy, a practical approach," in Encyclopedia of Analytical Chemistry, pp. 10815-10837, Wiley, 2000.

[14] C. Remazeilles, V. Quillet, T. Calligaro, J. C. Dran, L. Pichon, and J. Salomon, "PIXE elemental mapping on original manuscripts with an external microbeam. Application to manuscripts damaged by iron-gall ink corrosion," Nuclear Instruments and Methods in Physics Research Section B: Beam Interactions with Materials and Atoms, vol. 181, no. 1-4, pp. 681-687, 2001.

[15] E. Bulska, B. Wagner, and M. G. Sawicki, "Investigation of complexation and solid-liquid extraction of iron from paper by UV/VIS and atomic absorption spectrometry," Mikrochimica Acta, vol. 136, no. 1-2, pp. 61-66, 2001.

[16] M. D. Guillén and N. Cabo, "Relationships between the composition of edible oils and lard and the ratio of the absorbance of specific bands of their Fourier transform infrared spectra. Role of some bands of the fingerprint region," Journal of Agricultural and Food Chemistry, vol. 46, no. 5, pp. 1788-1793, 1998.

[17] M. P. Richard and M. Podhajny, "A Lesson in Amines Used in Water-Based Products," 2010, http://pffc-online.com/mag/ paper_lesson_amines_used/.

[18] A. Silva, R. Reina, J. García-Casco, and J. Ventanas, "Chemicalinstrumental-sensory parameters and chemometrics as tools to discriminate among the quality categories of dry-cured Iberian shoulder," Grasas y Aceites, vol. 64, no. 2, pp. 201-209, 2013. 

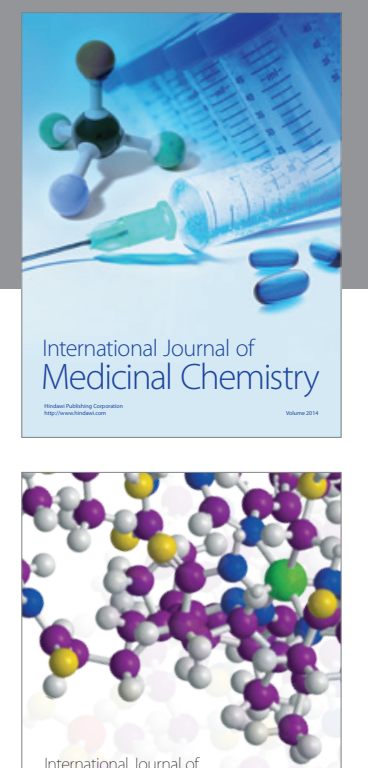

\section{Carbohydrate} Chemistry

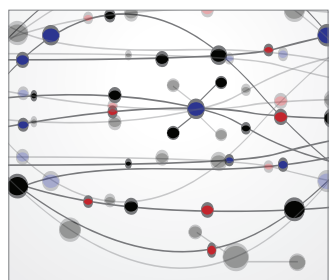

The Scientific World Journal
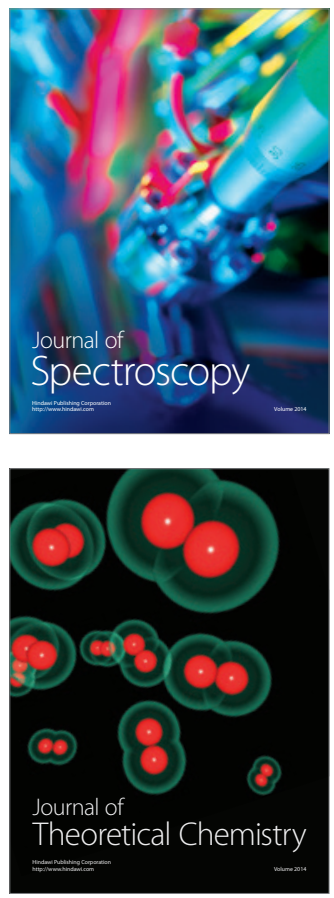
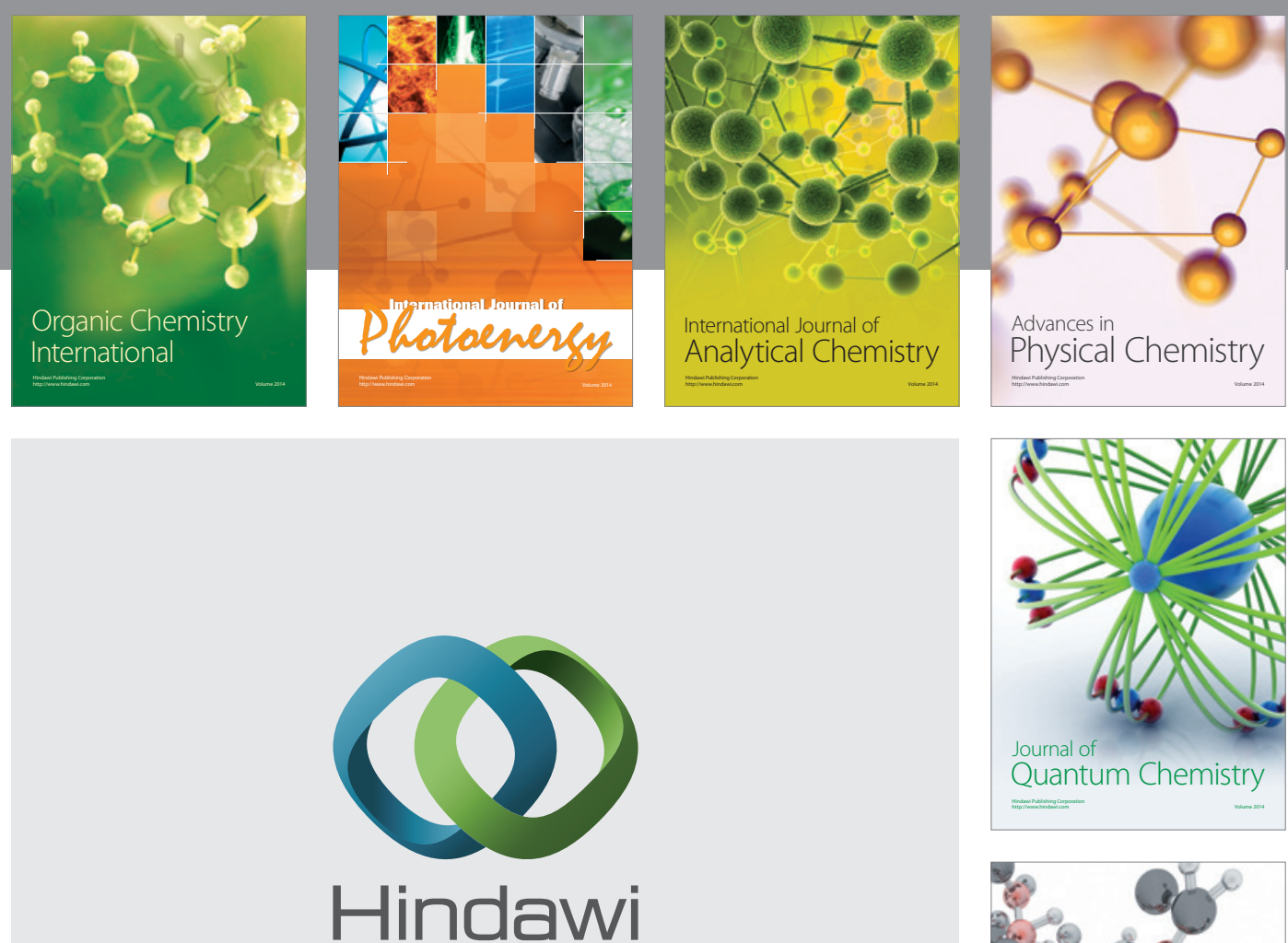

Submit your manuscripts at

http://www.hindawi.com

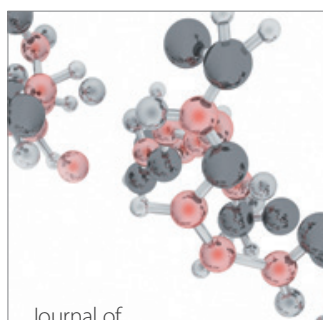

Analytical Methods

in Chemistry

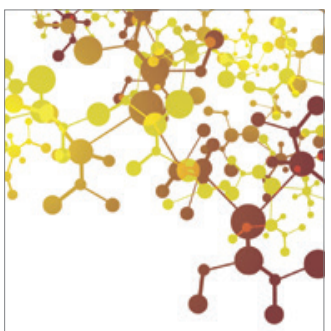

Journal of

Applied Chemistry

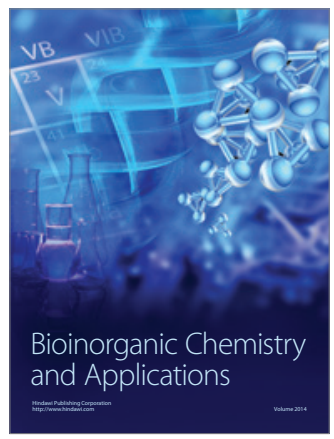

Inorganic Chemistry
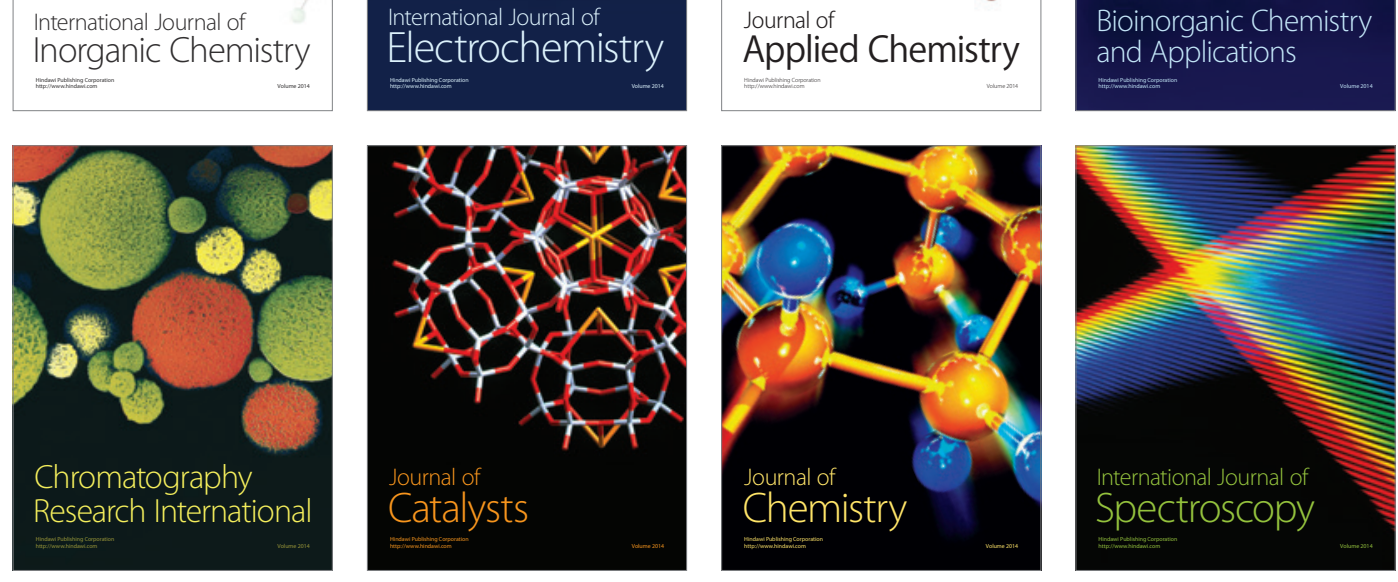